\title{
Paternal effects correlate with female reproductive stimulation in the polyandrous ladybird Cheilomenes sexmaculata
}

\author{
M.A. Mirhosseini ${ }^{1}$, J.P. Michaud ${ }^{2 *}$, M.A. Jalali ${ }^{1}$ \\ and M. Ziaaddini ${ }^{1}$ \\ ${ }^{1}$ Department of Crop Protection, Agriculture College, Vali-e-Asr University \\ of Rafsanjan, Rafsanjan, Iran: ${ }^{2}$ Department of Entomology, Kansas State \\ University, Agricultural Research Center-Hays, Hays, Kansas, USA
}

\begin{abstract}
Components of male seminal fluids are known to stimulate fecundity and fertility in females of numerous insect species and paternal effects on offspring phenotype are also known, but no studies have yet demonstrated links between male effects on female reproduction and those on progeny phenotype. In separate laboratory experiments employing 10-day-old virgin females of Cheilomenes sexmaculata (F.), we varied male age and mating history to manipulate levels of male allomones and found that the magnitude of paternal effects on progeny phenotype was correlated with stimulation of female reproduction. Older virgin males remained in copula longer than younger ones, induced higher levels of female fecundity, and sired progeny that developed faster to yield heavier adults. When male age was held constant (13 days), egg fertility declined as a function of previous male copulations, progeny developmental times increased, and the adult weight of daughters declined. These results suggest that male epigenetic effects on progeny phenotype act in concert with female reproductive stimulation; both categories of effects increased as a consequence of male celibacy (factor accumulation), and diminished as a function of previous matings (factor depletion). Male factors that influence female reproduction are implicated in sexual conflict and parental effects may extend this conflict to offspring phenotype. Whereas mothers control the timing of oviposition events and can use maternal effects to tailor progeny phenotypes to prevailing or anticipated conditions, fathers cannot. Since females remate and dilute paternity in polyandrous systems, paternal fitness will be increased by linking paternal effects to female fecundity stimulation, so that more benefits accrue to the male's own progeny.
\end{abstract}

Keywords: development, fecundity, fertility, sexual conflict

(Accepted 19 February 2014; First published online 24 March 2014)

*Author for correspondence

Phone: 785-625-3425

Fax: 785-623-4369

Email: jpmi@ksu.edu

\section{Introduction}

Maternal effects, the epigenetic modification of offspring development by mothers, can have dramatic consequences for progeny phenotype and life history (Mousseau \& Dingle, 1991; Mousseau et al., 2009). Transgenerational signals of maternal origin have received considerable research attention, especially in insects, since the publication of 
Mousseau \& Fox (1998). Until recently, less attention was directed toward the potential significance of paternal effects (but see Hunt \& Simmons, 2000; Bonduriansky \& Head, 2007; Adler \& Bonduriansky, 2013). Insect seminal fluids have been a focus of research attention largely because of their many effects on female reproductive functions, ranging from inhibition of receptivity on the one hand, to stimulation of fecundity and fertility on the other (Chen et al., 1988; Gillott, 2003; Avila et al., 2011). Seminal fluids also transmit the paternal epigenome, whether via genomically imprinted sperm, or transcribed factors such as allohormones, as exemplified by the sex peptide of Drosophila melanogaster (Gioti et al., 2012). However, the role of insect seminal fluids in mediating transgenerational signals of paternal origin is not yet fully understood.

If the influence of paternal effects on offspring is underestimated, their potential roles in sexual conflict remain largely unexplored (but see Qvarnstrom \& Price, 2001). Intersexual conflict arises when the reproductive interests of male and female are not congruent (Eberhard, 1996, 1997). When both parents exert parental effects, the potential exists for sexual conflict over offspring phenotype development (e.g., Miller et al., 2006; Simmons \& Garcia-Gonzalez, 2007). As noted by Brown et al. (1997), the degree of control exerted by each sex over events in the mating sequence can have a strong influence on evolution of the mating system and on the level of sexual conflict. Female insects clearly hold the balance of power in this regard, having effectively decoupled the process of fertilization from insemination through evolution of sperm storage in the spermatheca, selecting in turn for male abilities to coerce aspects of female reproduction and so regain some control of the process (Eberhard, 1996).

In the case of aphidophagous coccinellids, which are highly promiscuous, unidentified male factor(s) appear to stimulate egg production by females. This has been demonstrated using repeated matings to boost male factor levels in females, first in Adalia bipunctata (Semyanov, 1970) and subsequently in a number of other species (Majerus, 1994; Omkar \& Mishra, 2005; Omkar \& Pervez, 2005), including Cheilomenes sexmaculata (F.) (Bind, 2007). In Propylea dissecta and C. sexmaculata, the optimum number of matings required to maximize female fitness in the laboratory was estimated to be about 13 (Omkar et al., 2006a, b). But repeated matings can be costly for males; a study in two Coccinella spp. revealed that serial copulations progressively diminished male ability to stimulate female reproduction, suggesting male factor(s) are subject to depletion (Michaud et al., 2013). The same study found negative consequences of previous paternal matings for progeny fitness (lower survival, slower development, smaller adult size), which suggested possible linkage between female reproductive stimulation and paternal effects. The age of beetles was held constant in most of the studies cited above, but age at first mating can also have a significant effect on female reproductive performance. For example, Omkar et al. (2010) showed that fecundity and egg fertility in Coelophora saucia (Mulsant) was maximized when females and males were about 20 and 30 days old at first mating, respectively. This increase in female reproductive performance with male age up to 30 days could be inferred to reflect male factor accumulation during the period of mate deprivation.

Given that coccinellid males have no direct control over egg fertilization by females, the timing of oviposition, or the placement of eggs, we hypothesized that paternal effects on progeny will not be contingent on any specific environmental conditions, but rather should be expressed in a fixed pattern, i.e., they will be 'selection-based', rather than 'detection-based' (sensu Shea et al., 2011). Since female polyandry results in a progressive dilution of the first male's paternity, males in such systems would benefit from coupling paternal effects with female fecundity stimulation, thus ensuring that their epigenetic investment contributes primarily to the condition of their own progeny. In the present study, we varied both male age at first mating and male mating history in C. sexmaculata in order to effect the accumulation and depletion of male factor, respectively, and observed the consequences for both female reproductive performance and offspring development. We hypothesized that prolonged male celibacy would lead to accumulation of male factor, so that female reproductive performance (as measured by time to oviposition, fecundity and fertility) and offspring quality (as measured by survival, developmental rate and body mass) would both improve with male age at first mating. The second hypothesis was that matings will deplete male factor, so that male influences on both female reproduction and offspring condition will diminish as a function of the number of previous male copulations for males of a given age.

\section{Materials and methods}

Insect colony

A colony of C. sexmaculata was established from about 100 adult beetles collected from a pistachio orchard (GPS coordinates $30^{\circ} 23^{\prime} 39.07^{\prime \prime} \mathrm{N}$ and 55 $55^{\prime} 39.30^{\prime \prime} \mathrm{E}$ ) infested with pistachio psyllid, Agonoscena pistaciae Burckhardt and Lauterer at Vali-e-Asr University of Rafsanjan, Rafsanjan, Iran in September 2012. Prior to use in experiments, the beetles were reared for two generations on frozen eggs of Ephestia kuehniella Zeller (Lepidoptera: Pyralidae) in a climatecontrolled growth chamber set to $26 \pm 1^{\circ} \mathrm{C}, 60 \pm 5 \% \mathrm{RH}$ and 16L: 8D photoperiod. Adults were held in a ventilated plastic box $(20.0 \times 30.0 \times 10.0 \mathrm{~cm})$ and fed initially with psyllidinfested leaves of pistachio. Eggs of E. kuehniella were obtained from a colony maintained in the insectary of the University of Rafsanjan and were never stored for more than 1 month prior to use. Mated females were isolated in plastic Petri dishes $(6.0 \mathrm{~cm}$ diameter $\times 1.5 \mathrm{~cm}$ height) and paired with a male from the stock colony for 2-3h every other day during the course of oviposition to maintain fertility. Eggs were collected every $12 \mathrm{~h}$ and females were fed E. kuehniella eggs daily. Upon hatching, first instar larvae were transferred to plastic Petri dishes (6.0 cm diameter), one per dish, and fed eggs of E. kuehniella daily until they emerged as adults. Callow adults were transferred to plastic boxes (as above), about 25 pairs per box, where they were fed eggs of E. kuehniella daily.

\section{Experiments}

All experiments were conducted in growth chambers under constant physical conditions $\left(27.5 \pm 1^{\circ} \mathrm{C}, 55 \pm 10 \% \mathrm{RH}\right.$ and 16L: 8D photoperiod). Forty mated female C. sexmaculata from the stock colony were isolated in plastic Petri dishes $(6.0 \mathrm{~cm})$ and provisioned with E. kuehniella eggs ad libitum, refreshed twice daily. Petri dishes were observed twice daily and changed following each oviposition. Egg clusters were kept in an incubator until eclosion under the same physical conditions as larvae. First instar larvae were isolated in Petri dishes and fed every $12 \mathrm{~h}$ until pupae formed. Adult beetles were weighed on an electronic balance (accuracy $=0.1 \mathrm{mg}$ ) 
Table 1. Copulation, reproduction and progeny development data (means \pm SE) for C. sexmaculata pairs in which 10-day-old virgin females were mated once with a virgin male either 5,15 or 30 days old. Means bearing the same letter were not significantly different within columns (Bonferroni, $\alpha=0.05$ ).

\begin{tabular}{|c|c|c|c|c|c|c|c|}
\hline $\begin{array}{l}\text { Male age } \\
\text { (day) }\end{array}$ & $n$ & $\begin{array}{c}\text { Time to } \\
\text { copula (min) }\end{array}$ & $\begin{array}{l}\text { Duration of } \\
\text { copula (min) }\end{array}$ & $\begin{array}{l}\text { Fecundity } \\
\text { (no. eggs) }\end{array}$ & $\begin{array}{c}\text { Fertility } \\
\text { (\% hatching) }\end{array}$ & $\begin{array}{c}n \\
\text { (progeny) }\end{array}$ & $\begin{array}{c}\text { Progeny development } \\
\text { time (days) }\end{array}$ \\
\hline Five & 20 & $4.18 \pm 0.70 \mathrm{a}$ & $130.7 \pm 9.9 b$ & $159.8 \pm 25.5 b$ & $83.2 \pm 2.0 \mathrm{~b}$ & 85 & $11.26 \pm 0.10 \mathrm{a}$ \\
\hline Fifteen & 20 & $2.85 \pm 0.65 \mathrm{ab}$ & $170.6 \pm 12.6 a$ & $241.9 \pm 40.2 \mathrm{ab}$ & $80.9 \pm 5.5 \mathrm{ab}$ & 60 & $11.25 \pm 0.10 \mathrm{a}$ \\
\hline$F$ & & 2.30 & 6.17 & 5.79 & 0.09 & & 17.93 \\
\hline $\mathrm{df}$ & & 2,53 & 2,53 & 2,47 & 2,47 & & 2,207 \\
\hline$P$ & & 0.11 & 0.004 & 0.006 & 0.915 & & $<0.001$ \\
\hline
\end{tabular}

within $12 \mathrm{~h}$ of emergence and sexed. Males and females were distinguished by the shape of the terminal abdominal segment, which is more rounded in females and more pointed in males when viewed ventrally. The average fresh mass of female parents was $9.53 \pm 0.26 \mathrm{mg}$ and of male parents, $6.72 \pm 0.17 \mathrm{mg}$ ( $n=70$ in each case).

For the male age experiment, all beetles were isolated in Petri dishes and fed daily until they reached the required age. Virgin males aged 5, 15 and 30 days ( $n=20$ per treatment) were each paired once with a 10-day-old virgin female in a Petri dish. Time to copula was tallied as the time elapsed between introduction of male and female into the dish until onset of copula. Duration of copula was tallied as the time between onset of copula and male dismount. After a copulation, females were isolated in Petri dishes with E. kuehniella eggs and observed twice daily for 20 days. Egg retention time (ERT) for females post-copula was tallied as the median time between observations during the period when the eggs were laid. Fecundity (no. of eggs laid) and egg fertility (percentage of eggs hatching) were recorded for each female, along with the developmental time (egg incubation+larva + pupa) and adult fresh weight of five of her offspring. Fresh weight and sex were recorded for all offspring within $24 \mathrm{~h}$ of emergence.

For the mating history experiment, females from the stock colony were used to create males with different mating histories. Once-mated males were permitted a single copulation on their 11th day of adult life, five-times-mated males, five copulations on days 7-11; and ten-times-mated males daily copulations from days 2 to 11 inclusive. All copulations were visually confirmed. No copulations were permitted on the 12th day and all males were 13 days old when paired with a single focal, 10-day-old, virgin female. The same physical conditions were employed as in the previous experiment and all the same biological parameters were measured.

\section{Data analysis}

Data were checked for normality using the KolmogorovSmirnov test (K-S test) and all were found to be normally distributed. Percentages (e.g., egg fertility) were arcsine square root-transformed prior to analysis. Data on time between introduction to start of mating, duration of copulation, fecundity, percentage egg hatch and developmental time for immature stages were subjected to one-way ANOVA followed by a Bonferroni test to separate means ( $\alpha=0.05$; SPSS, 2006), with either male age or mating history as the independent factor. A two-way ANOVA was used to test effects of male age/mating history and offspring sex on offspring weight. Percent survival and offspring sex ratio were analyzed by Chi-square $\left(\chi^{2}\right)$.

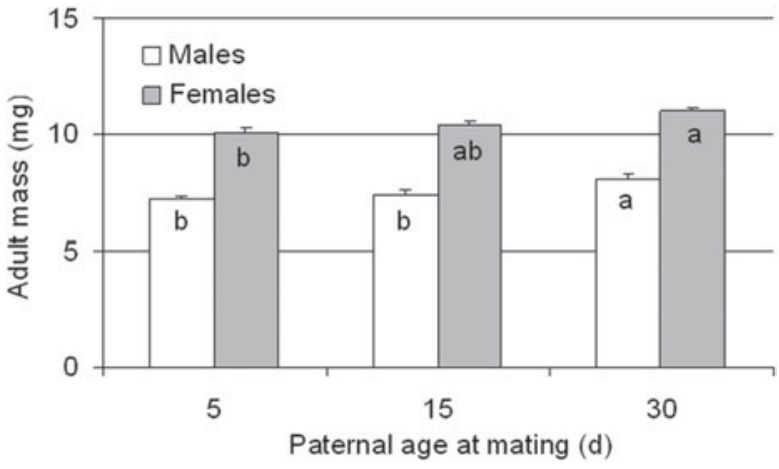

Fig. 1. Mean $\pm \mathrm{SE}$ adult fresh mass of Cheilomenes sexmaculata progeny sired by virgin males either 5,15 or 30 days old with 10day-old virgin females. Columns bearing the same letter were not significantly different from others of the same sex (Bonferroni, $\alpha=0.05$ ).

\section{Results \\ Effects of male age at first mating}

There were significant effects of male age on duration of copula and female fecundity, but not on the time to initiate copula, or egg fertility (table 1). Older males tended to remain longer in copula and stimulated female fecundity more than younger males. One female in treatments one and three and four females in treatment two failed to oviposit and were excluded from analyses of fecundity and fertility. There were significant effects of male age on the total developmental time of progeny from egg to adult; faster development was obtained by the offspring of the oldest fathers, although the magnitude of the difference between five and 30-day-old fathers was $<1$ day over the entire period of development. Mean offspring survival was $93.3 \pm 2.8,81.2 \pm 5.0$ and $94.3 \pm 3.3 \%$ for $5-, 15$ - and 30-day-old sires, respectively, the difference between 15- and 30-day-old sires being the only significant difference $\left(\chi^{2}=4.84, P=0.028\right)$. The sex ratio of offspring did not vary among treatments $\left(\chi^{2}=0.829, \mathrm{df}=2\right.$, $P=0.661)$ and was not significantly different from $50 \%$ $\left(\chi^{2}=0.5, P=0.480\right)$. A two-way ANOVA of paternal age and offspring sex on offspring fresh mass was significant overall $\left(F_{5202}=83.08, P<0.001\right)$ and revealed significant main effects of age $\left(F_{2202}=12.32, P<0.001\right)$ and $\operatorname{sex}\left(F_{1202}=376.84, P<0.001\right)$ without significant interaction $\left(F_{2202}=0.01, P=0.987\right)$. Females were heavier than males and offspring of older fathers tended to be heavier than those of younger fathers, regardless of whether they were male or female (fig. 1). 
Table 2. Copulation, reproduction and progeny development data (means \pm SE) for C. sexmaculata pairs in which 10-day-old virgin females were mated once with a 13-day-old male that was either virgin or mated once, five or ten times previously. Means bearing the same letter were not significantly different within columns (Bonferroni, $\alpha=0.05$ ).

\begin{tabular}{|c|c|c|c|c|c|c|c|}
\hline $\begin{array}{l}\text { Male mating } \\
\text { history }\end{array}$ & $n$ & $\begin{array}{l}\text { Time to } \\
\text { copula (min) }\end{array}$ & $\begin{array}{c}\text { Duration of } \\
\text { copula (min) }\end{array}$ & $\begin{array}{l}\text { Fecundity } \\
\text { (no. eggs) }\end{array}$ & $\begin{array}{c}\text { Fertility } \\
(\% \text { hatching })\end{array}$ & $\begin{array}{c}n \\
\text { (progeny) }\end{array}$ & $\begin{array}{l}\text { Progeny development } \\
\text { time (day) }\end{array}$ \\
\hline Virgin & 16 & $1.13 \pm 0.26 b$ & $151.4 \pm 13.1 a$ & $260.7 \pm 54.7 a$ & $86.0 \pm 1.6 \mathrm{a}$ & 62 & $10.63 \pm 0.08 c$ \\
\hline Mated $\times 1$ & 13 & $2.19 \pm 0.36 \mathrm{ab}$ & $118.1 \pm 14.9 a$ & $180.2 \pm 34.6 a$ & $74.6 \pm 3.7 \mathrm{ab}$ & 55 & $10.95 \pm 0.07 \mathrm{ab}$ \\
\hline Mated $\times 10$ & 15 & $3.40 \pm 0.55 a$ & $117.9 \pm 7.0 \mathrm{a}$ & $150.0 \pm 33.5 a$ & $70.1 \pm 4.1 b$ & 48 & $10.79 \pm 0.06 b c$ \\
\hline$F$ & & 7.51 & 2.46 & 1.71 & 4.49 & & 7.01 \\
\hline df & & 3,54 & 3,54 & 3,51 & 3,51 & & 3,205 \\
\hline
\end{tabular}

\section{Effects of male mating history}

There were significant effects of male mating history on the time required to initiate copula and egg fertility, but not on duration of copula or fecundity (table 2). One female failed to oviposit in each of the first three treatments and was excluded from analysis of fecundity and fertility. Time to copula tended to increase with number of previous paternal matings, suggesting a reduction in male mating proclivity with increased numbers of copulations.

Differences in female fecundity did not reach significance at $P=0.05$ because of high within-group variation among females. However, there was a clear downward trend in fecundity with number of previous male matings, and a negative quadratic regression line could be fitted to the four data points with $r^{2}>0.85$. Egg fertility declined progressively and significantly and there were also significant effects of male mating history on the total developmental time of progeny. Although the progeny of $5 \times$ mated males required the longest time to complete development, those of $10 \times$ mated males developed as quickly as virgin males. Mean survival was $86.7 \pm 4.6,88.3 \pm 3.8,75.0 \pm 6.0$ and $83.6 \pm 3.6 \%$ for offspring of virgin, one, five and ten times mated males, respectively $\left(\chi^{2}=9.49, \mathrm{df}=3, P=0.023\right)$ and revealed no clear trend. The sex ratio of offspring did not vary among treatments $\left(\chi^{2}=3.76\right.$, $\mathrm{df}=3, P=0.289)$ and was not significantly different from $50 \%$ $\left(\chi^{2}=2.48, \mathrm{df}=1, P=0.116\right)$. The two-way ANOVA of paternal mating history and offspring sex on offspring fresh mass was significant overall $\left(F_{7,202}=34.72, P<0.001\right)$ and revealed significant main effects of mating history $\left(F_{3201}=5.15, P=0.035\right)$ and $\operatorname{sex}\left(F_{1201}=380.51, P<0.001\right)$, without a significant interaction $\left(F_{3201}=1.51, P=0.213\right)$. The mass of daughters decreased with increased number of paternal matings but the mass of sons did not (fig. 2).

\section{Discussion}

The first experiment revealed that increasing paternal age at first mating up to 30 days of adulthood is associated with increased female reproductive performance, as measured by 20-day fecundity (table 1). Previously, Omkar et al. (2006a, b) found that female fecundity in C. sexmaculata increased with male age up to 60 days, provided males were prevented from mating during this period. Also similar to the observations of Omkar et al. (2006a,b), older C. sexmaculata males initiated copula more quickly and exhibited longer copulations, which are thought to correlate with the transfer of larger volumes of seminal fluid (Obata, 1987). A very similar pattern was observed for C. saucia Mulsant (Coleoptera: Coccinellidae); in a study that spanned a greater range of male ages, fecundity

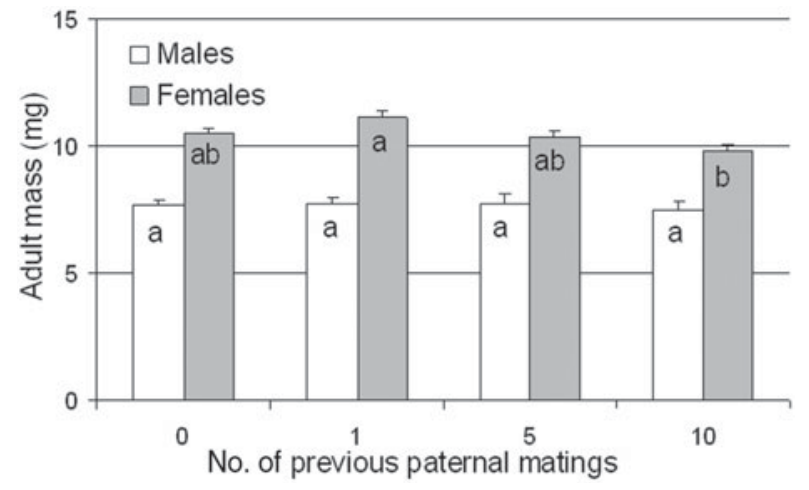

Fig. 2. Mean $\pm \mathrm{SE}$ adult fresh mass of Cheilomenes sexmaculata progeny sired by 13-day-old males of different mating histories with 10-day-old virgin females. Columns bearing the same letter were not significantly different from others of the same sex (Bonferroni, $\alpha=0.05$ ).

stimulation peaked at 30 days and declined thereafter (Omkar et al., 2010). Likewise, Srivastava \& Omkar (2004) found fertility in Coccinella septempunctata L. to be dependent on paternal age, peaking for males 20-30 days old. Although an increase in sperm number with age could contribute to some of these effects, male allohormonal factors would seem to be implicated, as egg maturation should not depend on the number of sperm available.

Male age effects on female reproduction were mirrored by paternal effects on offspring fitness, confirming our primary hypothesis; 30-day-old males sired progeny that developed faster (table 1) and yielded heavier adults (fig. 1) than did 15-day-old males, with better survival to the adult stage. This appears consistent with previous observations by Omkar \& Singh (2009) who found that younger adults of C. sexmaculata produced faster developing offspring than did older pairs, although the ages of both parents were varied in that study. We infer that either the same male factors stimulating female fecundity in C. sexmaculata are responsible for the paternal effects on offspring development, or independent factors are responsible, which are accumulated/depleted in tandem. For example, the male sex peptide of $D$. melanogaster elicits a cascade of genetic expression in mated females (Gioti et al., 2012) and even demonstrates cross-species activity in other insect orders (Hanin et al., 2012), although any possible effects on progeny phenotype have not been explored. Once again, simple differences in sperm numbers received during mating are unlikely to affect progeny development post-fertilization, 
so changes in other components of seminal fluids would seem to be implicated.

The results of the mating history experiment, in which treatments effectively imposed different levels of male factor depletion prior to a focal mating, partly confirmed the second hypothesis. Female fertility declined with increasing numbers of previous paternal matings, although changes in fecundity were not significant due to high variation within treatments (table 2). As numbers of previous paternal matings increased, progeny developed more slowly to yield lighter female adults, although the mass of male progeny appeared unaffected (fig. 2). Previous work has shown that matings are costly for coccinellid males and diminish their ability to invest in subsequent copulations, both behaviorally and physiologically (Michaud et al., 2013; Omkar et al., 2013). We infer that reserves of male allomonal factor(s) accumulate slowly through adult life, prior to onset of senescence, until they are depleted by mating events.

Female coccinellids control the timing of oviposition and the placement of eggs, and can alter progeny phenotypes to suit predictable dynamics of resource availability, even when this requires producing higher condition progeny later in the reproductive cycle, rather than early (e.g., Vargas et al., $2012 a, b)$. Such tactics are beyond the ability of males that have little, if any, control over sperm utilization by females. In polyandrous systems, paternal effects will be most profitably coordinated with female fecundity stimulation because paternity is diluted over time by female remating (Wedell et al., 2006). Thus, male $C$. sexmaculata coerce the early and rapid production of high-quality offspring by females, to the extent they are able.

Fecundity stimulation would seem a rather inefficient male strategy for maximizing paternity, but may represent an alternative strategy for males when females are able to resist male inhibition of female receptivity post-copula. Clearly, females can only benefit from paternal effects that improve offspring condition, and probably rely upon them to realize their own fitness potential, but matings beyond some optimum number will reduce female fitness (i.e., Omkar et al., 2006a). Sexual conflict may arise over female reproductive rate, simply because males will strongly discount residual (future) female reproductive effort and favor a higher rate of oviposition than that which may be optimal for female lifetime fitness. Indeed, laboratory studies which have demonstrated reductions in female longevity as a cost of repeated matings (i.e., Mishra \& Omkar, 2006) may well underestimate them, as longevity is greatly extended by artifacts of confinement (reduced energy expenditure, protection from predation, ad libitum food, etc.). However, most studies of coccinellids that have followed lifetime reproductive success reveal no indication of a fecundity/longevity tradeoff; rather, the most fecund individuals seem to be the longest lived (e.g., Michaud \& Qureshi, 2006; Omkar et al., 2010). It is also possible that male fecundity stimulation exacts a genetic cost for females; a sub-maximal oviposition rate might enable them to mate with a larger number of males and thus produce more genetically diverse progeny, or counter the infertility risks associated with mating with related males (Tregenza \& Wedell, 2002). It is our hope that the present work will provide impetus for exploration of paternal effects in other insect systems where male factors have been shown to stimulate female reproductive performance, especially in those for which the chemical factors responsible have been identified.

\section{Acknowledgments}

We are grateful to the Department of Plant Protection, Vali-e-Asr University of Rafsanjan the use of greenhouse facilities. This is contribution No. 14-093-J from the Kansas Agricultural Experiment Station.

\section{References}

Adler, M.I. \& Bonduriansky, R. (2013) Paternal effects on offspring fitness reflect father's social environment. Evolutionary Biology 40, 288-292.

Avila, F.W., Sirot, L.K., LaFlamme, B.A., Rubinstein, C.D. \& Wolfner, M.F. (2011) Insect seminal fluid proteins: identification and function. Annual Review of Entomology 56, 21-40.

Bind, R.B. (2007) Reproductive behaviour of a generalist aphidophagous ladybird beetle, Cheilomenes sexmaculata. International Journal of Tropical Insect Science 27, 78-84.

Bonduriansky, R. \& Head, M. (2007) Maternal and paternal condition effects on offspring phenotype in Telostylinus angusticollis (Diptera: Neriidae). Journal of Evolutionary Biology 20, 2379-2388.

Brown, W.D., Crespi, B.J. \& Choe, J.C. (1997) Sexual conflict and the evolution of mating systems. pp. 352-377 in Choe, J.C. \& Crespi, B.J. (Eds) The Evolution of Mating Systems in Insects and Arachnids. Cambridge, UK, Cambridge University Press.

Chen, P.S., Strumm-Zollinger, E., Aigaki, T., Balmer, J., Bienz, M. \& Bohlen, P. (1988) A male accessory gland peptide that regulates reproductive behavior of female Drosophila melanogaster. Cell 54, 291-298.

Eberhard, W.G. (1996) What is cryptic female choice? pp. 4-43 in Eberhard, W.G. (Ed.) Female Control: Sexual Selection by Cryptic Female Choice. Princeton, New Jersey, Princeton University Press.

Eberhard, W.G. (1997) Sexual selection by cryptic female choice in insects and arachnids. pp 32-57 in Choe, J.C. \& Crespi, B.J. (Eds) The Evolution of Mating Systems in Insects and Arachnids. Cambridge, UK, Cambridge University Press.

Gillott, C. (2003) Male accessory gland secretions: modulators of female reproductive physiology and behavior. Annual Review of Entomology 48, 163-184.

Gioti, A., Wigby, S., Wertheim, B., Schuster, E., Martinez, P., Pennington, C.J., Partridge, L. \& Chapman, T. (2012) Sex peptide of Drosophila melanogaster males is a global regulator of reproductive processes in females. Proceedings of the Royal Society of London, Series B 279, 4423-4432.

Hanin, O., Azrielli, A., Applebaum, S.W. \& Rafaeli, A. (2012) Functional impact of silencing the Helicoverpa armigera sexpeptide receptor on female reproductive behaviour. Insect Molecular Biology 21, 161-167.

Hunt, J. \& Simmons, L.W. (2000) Maternal and paternal effects on offspring phenotype in the dung beetle Onthophagus taurus. Evolution 54, 936-941.

Majerus, M.E.N. (1994) Female promiscuity maintains high fertility in ladybirds (Coleoptera: Coccinellidae). Entomologist's Monthly Magazine 130, 205-209.

Michaud, J.P. \& Qureshi, J.A. (2006) Reproductive diapause in Hippodamia convergens (Coleoptera: Coccinellidae) and its life history consequences. Biological Control 39, 193-200.

Michaud, J.P., Bista, M., Mishra, G. \& Singh, O. (2013) Sexual activity diminishes male virility in two Coccinella species: consequences for female fertility and progeny development. Bulletin of Entomological Research 103, 570-577. 
Miller, P.M., Gavrilet, S. \& Rice, W.R. (2006) Sexual conflict via maternal-effect genes in $\mathrm{ZW}$ species. Science 312,73 .

Mishra, G. \& Omkar (2006) Ageing trajectory and longevity trade-off in an aphidophagous ladybird, Propylea dissecta (Coleoptera: Coccinellidae). European Journal of Entomology 103, 33-40.

Mousseau, T.A. \& Dingle, H. (1991) Maternal effects in insect life histories. Annual Review of Entomology 36, 511-534.

Mousseau, T.A. \& Fox, C.W. (1998) Maternal Effects as Adaptations. New York, USA, Oxford University Press.

Mousseau, T.A., Uller, T., Wapstra, E. \& Badyaev, A.V. (2009) Evolution of maternal effects: past and present. Philosophical Transactions of the Royal Society of London, Series B, 364, 1035-1038.

Obata, S. (1987) Mating behavior and sperm transfer in the ladybird beetle, Harmonia axyridis Pallas (Coleoptera: Coccinellidae). Applied Entomology and Zoology 22, 434-442.

Omkar \& Mishra, G. (2005) Evolutionary significance of promiscuity in an aphidophagous ladybird, Propylea dissecta. Bulletin of Entomological Research 95, 527-533.

Omkar \& Pervez, A. (2005) Mating behaviour of an aphidophagous ladybird beetle, Propylea dissecta (Mulsant). Insect Science 12, 37-44.

Omkar \& Singh, S.K. (2009) Effect of parental ageing on offspring developmental and survival attributes in an aphidophagous ladybird, Cheilomenes sexmaculata. Journal of Applied Entomology 133, 500-504.

Omkar, Mishra, G. \& Singh, S.K. (2006a) Optimal number of matings in two aphidophagous ladybirds. Ecological Entomology 31, 1-14.

Omkar, Singh, S.K. \& Singh, K. (2006b) Effect of age on reproductive attributes of an aphidophagous ladybird, Cheilomenes sexmaculata. Insect Science 13, 301-308.

Omkar, Singh, S.K. \& Mishra, G. (2010) Parental age at mating affects reproductive attributes of the aphidophagous ladybird beetle, Coelophora saucia (Coleoptera: Coccinellidae). European Journal of Entomology 107, 341-347.

Omkar, Sahu, J. \& Kumar, G. (2013) Age specific mating incidence and reproductive behavior of the ladybird beetle, Anegleis cardoni (Weise) (Coleoptera: Coccinellidae). Journal of Asia-Pacific Entomology 16, 263-268.

Qvarnstrom, A. \& Price, T.D. (2001) Maternal effects, paternal effects and sexual selection. Trends in Ecology and Evolution 16, 95-100.

Semyanov, V.P. (1970) Biological properties of Adalia bibunctata L. (Coleoptera: Coccinellidae) in conditions of Leningrad region. Zashchita Rastenii ot Vreditelei i Boleznei 127, 105-112 (in Russian).

Shea, N., Pen, I. \& Uller, T. (2011) Three epigenetic information channels and their different roles in evolution. Journal of Evolutionary Biology 24, 1178-1187.

Simmons, L.W. \& Garcia-Gonzalez, F. (2007) Female crickets trade offspring viability for fecundity. Journal of Evolutionary Biology 20, 1617-1623.

SPSS (2006) Version 15.0. Chicago, Illinois, SPSS Inc.

Srivastava, S. \& Omkar (2004) Age-specific mating and reproductive senescence in the seven-spotted ladybird, Coccinella septempunctata. Journal of Applied Entomology 128, 452-458.

Tregenza, T. \& Wedell, N. (2002) Polyandrous females avoid costs of inbreeding. Nature 415, 71-73.

Vargas, G.A., Michaud, J.P. \& Nechols, J.R. (2012a) Cryptic maternal effects in Hippodamia convergens vary with maternal age and body size. Entomologia Experimentalis et Applicata 146, 302-311.

Vargas, G.A., Michaud, J.P. \& Nechols, J.R. (2012b) Maternal effects shape dynamic trajectories of reproductive allocation in the ladybird Coleomegilla maculata. Bulletin of Entomological Research 102, 558-565.

Wedell, N., Kvarnemo, C., Lessells, M. \& Tregenza, T. (2006) Sexual conflict and life histories. Animal Behaviour 71, 999-1011. 